\title{
Supply Chain Financial Transshipment Strategy When Customers Switching
}

\author{
Sijia Chen*, Zhenzhong Guan, Xiaoli Li \\ School of Economics and Management, Southwest Jiaotong University, Chengdu, China \\ Email: *diandianonce@163.com
}

How to cite this paper: Chen, S.J., Guan, Z.Z. and Li, X.L. (2022) Supply Chain Financial Transshipment Strategy When Customers Switching. Journal of Mathematical Finance, 12, 238-262.

https://doi.org/10.4236/jmf.2022.121014

Received: December 12, 2021

Accepted: February 19, 2022

Published: February 22, 2022

Copyright $\odot 2022$ by author(s) and Scientific Research Publishing Inc. This work is licensed under the Creative Commons Attribution International License (CC BY 4.0).

http://creativecommons.org/licenses/by/4.0/

\begin{abstract}
With the advent of information technology, retailers have easy access to forecast updates to adjust inventory as the selling season approaches. Rather than giving a second ordering chance, this paper takes lateral transshipment as an alternative, and investigates the transshipment policies in a supplier with two independent asymmetric retailers with a single selling season under both independent and competitive market scenarios. The results show that in the presence of the capital-constrained retailer's default risk, the capital sufficient retailer is not always preferring to transship out. In the numerical analysis, we find the transshipment policies under competitive scenario are stricter than those under independent scenario.
\end{abstract}

\section{Keywords}

Capital Constrained Retailer, Preventive Lateral Transshipment, Customers' Switching Behavior

\section{Introduction}

Uncertainly in supply chain has posed a great challenge for managers, many researchers have focused on inventory management to reduce risks and decrease system cost. Traditional design of inventory system is hierarchical, i.e., from the upper echelon to the lower echelon. On the contrary, Lateral transshipment refers to the stock movement within the same echelon of an inventory system which is extensively applied in practice to reduce inventory imbalances. The merit of transshipment lies in enhancing the effectiveness of an inventory management by better managing the stock already procured. Reallocation of inventory through transshipment with updated demand forecasts is designed to increase the profitability of the system [1]. Lateral transfer has received and will continue to receive a great deal of attention as an effective way of achieving greater flex- 
ibility and responsiveness [2].

Lateral transshipment is widely used in retail stores such as apparel, sporting goods, toys, etc. Managers in the retail industry have been encouraged to share inventory for better performance, such as Foot Locker (a shoe retailer) [3]. Traditional transshipment is triggered when one retailer faces a stock out [4] [5]. On the other hand, owing to the development of big data, transshipment also occurs when retailers adjust and balance their inventory or prevent future stockout. For instance, in ShaanXi Lihe Trade Co. Ltd, under-stock retailer can purchase fashions from (nearby) retailers before stocking out.

Capital constrained is also becoming more common in the retailer's sector. Limited working capital is a frequent constraint in retailer procurement decisions, in the presence of capital constraints, retailers are in need of short-term outsourcing financing to execute their procurement actions, which rely on retailers' physical assets. Also, there exists another financing scheme between competing retailers that they can trade their capacity according to mutually agreed contract terms. Furthermore, as receivable is more and more prevent among supply chain, it is less likely for transshipping out retailer to receive immediate cash from transshipment in retailer who is small size, start-up or awful financial condition. In this paper, we refer to supplying chain financial transshipment strategy as another way to increase inventory when the retailer has limited capital, and discuss retailers' operation strategy when one retailer is capital constrained and delay to pay for transshipment payment until sales ending.

This research is motivated by observations in fashion industry, i.e., BeLLE, a company that sells shoes of different brands through independent retailers in china, while the store size, capital level and inventory capacity of retailers are different. During the sales season, BeLLE is able to serve its customers in a timely fashion shoe through transshipment from surplus retailer to under-stock retailer under both retailers' market demand continue to realize. There are many other fashions company such as PIAYBOYS, L'ALPINA, also use the same way to rebalance their inventory. In this paper, we focus on a decentralized lateral transshipment system with two independent asymmetric capital level retailers in order to improve their own performance.

Distinguished from the traditional ones, transshipment in this research is performed in advance of the beginning of sales season to prevent future stock out, the model is cast in a newsvendor setting with taking transshipment as an alternative of a second ordering chance to take advantage of forecast demand updates. Capital sufficient retailer decides whether to share some inventory through transshipment at a fixed price. Under no transshipment, the capital constrained retailer would quit the market after selling out all its inventory. Under transshipment, the capital constrained retailer requests transshipment which set by both retailers' negotiation in ante sale period at the fixed transshipment price. We characterize the structure of the retailers' optimal decisions under both independent and competitive market scenarios. In independent scenarios, retailers' 
performance will be degraded for systems with impatient customers who are less tolerant to stock out, thus, in this model, customers with unmet demand under competitive market will forgo purchasing. While customers with unmet demand under competitive market have a choice to switch another retailer to get product. Their demand could be lost from the capital constrained retailer's perspective if they switch to other retailers. We refer to the customers' behavior of visiting the surplus retailer as "switching".

These two kinds of market conditions discussing above lead to some interesting question. 1) Can both the capital constrained retailer and the capital sufficient retailer benefit from transshipment? 2) When does the capital sufficient retailer accept or reject the transshipment request? 3) How does the transshipment contract affect customer's purchases behavior? 4) How does the customer's switching behavior affect capital sufficient retailer's decisions in transshipment?

This research devotes to answering these questions. Both independent market and competitive market are studied. We try to evaluate these two scenarios within a comparable framework. The existence of a unique Nash equilibrium of the transshipment quantity is shown under each market condition. Extensive numerical examples are provided to illustrate the advantage of transshipment. The result shows that transshipment does not always guarantee benefits for both retailers. Under the independent scenario, whether surplus retailer can benefit from transshipment depends on the transshipment quantity. Under the competitive market scenario, whether surplus retailer can benefit from transshipment depends on two variables: the transshipment quantity and the number of switch customers. We propose the optimal dynamic transshipment policies based on the number of switching customers, we show that market competition is an incentive to surplus retailer to reduce transshipment quantity. And our theoretical derivations are hinged upon the assumptions of customers switching, which are inspired by common customer behaviors building upon our characterization of the optimal transshipment. In the numerical experiments, we find the transshipment decisions under competitive scenario are stricter than those under the independent scenario.

The remainder of this paper is organized as follows. The next section provides a brief literature review. The problem description and assumption are presented in Section 3. Based on Section 3, we analyze the transshipment conditions in Section 4. The preventive transshipment model of two retailers is formulated and the corresponding preventive transshipment policy is obtained with differential market scenarios, and we compare the impact of different market in Section 5. We present a computational analysis in Section 6. Section 7 draws the conclusions.

\section{Literature Review}

There are two streams of literature which are relevant to this work. The first stream of literature deals with papers on the capital constrained supply chain in 
a classical newsvendor problem. The second steam of research deals with transshipment inventory decisions.

Classical studies of supply-chain ordering decisions usually assume that all the members in the supply chain have sufficient capital [6] [7] [8], operation which depends on outside support is rarely covered. In recent years, capital constrained supply chain management has emerged as an important research area with interest from both academic researchers and industrial practitioners [9] [10]. Several more closely related papers in this stream have examined how financial constraints influence supply chain performance, among the first to bring capital constraints within a simple newsvendor model (i.e., analysis of the retailer's stage and not of the overall supply chain) is the work of $\mathrm{Xu}$ and Birge [11]. The authors try to understand the impact of capital structure on the retailer's operational decisions. Dada and $\mathrm{Hu}$ [4] study a cash constrained retailer's optimal ordering quantity when facing a profit-maximizing bank. Lai et al. [12] discusses how a cash-constrained supplier makes its operation decision, they proposed preorder or consignment mode. Caldentey and Chen [13] propose a contract where the supplier offers partial credit to the budget-constrained retailer to help retailer continue operate. Kouvelis and Zhao [14] study the operation of a cashconstrained newsvendor under optimal price-only contract when bankruptcy is costly. The interaction between financing and ordering decisions has received a great deal of attention recently [15] [16] [17]. However, most of these studies focus on ways to get financing sources from different echelon in the framework of the classical newsvendor problem. However, none of this research has considered support from the same echelon in a supply chain, particularly competitor's mutual resources support when facing one of them is capital constraint and in need of financing.

Another stream of research related to our research concerns transshipment inventory decisions. Inventory sharing through transshipment is one of the emergency methods used to decrease lost sales and backorders [18]. Das [19] is among the first to look into the transshipment problem. Transshipment is allowed at predetermined times within the replenishment cycle. The author proves the optimality of the base stock conserving transfer rule under certain regularity conditions. Rudi et al. [1] examines the inventory choice with transshipment in a decentralized environment. Zou et al. [20] analyze the implementation of transshipment among competing companies and the impact of transshipment on their inventory replenishment decisions. Paterson et al. [21] provides a comprehensive literature review on lateral transshipment. They identify two main strands of literature on lateral transshipment that differ in the timing of transshipment, i.e., proactive transshipment and reactive transshipment. Çömez et al. [22] examine the initial order quantity and the acceptance or rejection decision of each transshipment request in a decentralized system of competing retailers and show that retailers' optimal transshipment policies are dynamic. Liang et al. [23] study a firm's optimal transshipment problem and they show that the op- 
timal transshipment strategy. Feng et al. [3] investigate two kinds of transshipment policies (ELT and PLT), and analyze the ELT policy by considering positive transshipment lead time and partial backordering. Shi [24] studies a twoechelon supply chain network consisting of one group node and multiple distribution nodes with a dual-channel sales model, and proposes an order processing strategy that uses offline inventory to transport and replenish when online inventory is out of stock. However, this research is related to study on efficient transfer price and transfer timing point, hardly ever mentioned the optimal transfer quantity as a decision to maximum profit in the later selling, while in competitive market, each company is profit-maximizing, it is necessary to consider their optimal strategy to maximize profit when they make up decisions.

Most of the previous research examines the inventory problem with market realizing. Owing to the development in technology, it is obvious that the forecast updates can be used in the design of the inventory strategy to better adjust the inventory, however, it has not been clearly dealt with in the transshipment literature. Therefore, with the help of information technology, retailers have easy access to forecast updates as the selling season approaches. Rather than giving a second order chance, this paper takes transshipment as an alternative to take advantage of forecast updates. Based on observations in practical application, this paper establishes the model for the replenishment and transshipment problem with forecast updates in a decentralized inventory system. This phenomenon has motivated the analysis of these issues under the demand forecast update and companies will balance their inventory according to update demand to prevent future stock out. It is distinguishable from existing studies in the following aspects: 1) transshipment decisions are investigated in a decentralized inventory system to take advantage of the demand forecast updates. 2) The existence of unique Nash equilibrium for transshipment of two retailers is proven with different market scenarios. 3) Extensive numerical examples are conducted to verify the effectiveness the proposed policy and provide some valuable management implications.

\section{Problem Description}

\subsection{Sequence of Event}

Consider a decentralize system with two retailers operating under a same supplier independently to satisfy demand over a single selling season with independent scenario or competitive scenario. Following the newsvendor scenario, each retailer stocks on a non-negative inventory in advance of the realization of stochastic demand. With the advent of information technology, retailers have easy access to forecast updates as the selling season approaches. Due to long lead time and operations difficult, they take transshipment as an alternative to take advantage of forecast updates to balance inventory rather than giving a second order chance.

The two retailers are asymmetrical. For capital constrained retailer i (she): 
Due to the long lead time of product and limited handing cash, it is unlikely for her to make second order from supplier in short time, transshipment is her only way to replenish inventory. With no transshipment, her sales season ends after sold out all her initial product out. With transshipment, she can get an extra amount of product under ante transshipment contract. For capital sufficient retailer $j$ (he): due to bullwhip effect and inaccurate prediction, he may over order when ordering for the first time. With no transshipment, if he can't sell out all products at the end of normal sales season, he has to liquidate the residual product at a salvage price in a short time. With transshipment, he can make decision whether agree ante transshipment contract or not, if so, and decides transship amount at the beginning of the sales reason under considering some of unsatisfied customer may switch to his own market with competitive market scenario. Figure 1 illustrates an overview of the market conditions.

To summarize the timings of the retailer's decisions and observations, we plot Figure 2 to illustrate the sequence of events in the two stages, where retailer $i$ is the capital constrained retailer while retailer $j$ is the capital sufficient retailer. In stage 1 , the two retailers that stock their own individual inventory are $q_{i}$ and $q_{j}$ according to their historical data analyses before demand are realized. Note that, as retailer i is capital constrained, we assume that all her initial capital is used to make order, so the order quantities $q_{i}$ is limited by initial capital $k$, thus $q_{i}=\frac{k}{w}$. As the sales season approaches, the two retailers have more accurate prediction on their market demand with the support of information technology, transshipment is another chance to balance their inventory, so they decide whether should transship and at what amount according to their update prediction through effective big data analysis still without knowing the demand in stage 2. The retailers decide on whether to participate in the transshipment nor not, if so, do two retailers negotiate how many to transship, note that after agreeing to transship, both of them must abide by the transshipment contract.

If transshipment occurs between two retailer, retailer i will delay transshipment payment until the sales season ends due to capital constrained, i.e., if the two retailers agree to transshipment, then transshipment payment will not be received until the sales season ends, therefore, retailer $j$ may take the default risk of retailer $i$, as cash flow of retailer $i$ depends on the sales income, if the sales income is less than transshipment payment, retailer i has no ability to pay full to retailer $j$, and also because retailer $i$ is limited liability, retailer $j$ would loss a part of profits due to the low cash flow affected by low demand, we will discuss it later.

In our model, the retailers' decision is transshipment quantity $T$, we can easily found retailers' inventory quantity $I$ before the demand realization when they participate transshipment or not, and customers from beliefs $\phi$ over the probability of availability on the salvage market (which depends on the retailers' inventory $I$ ). 


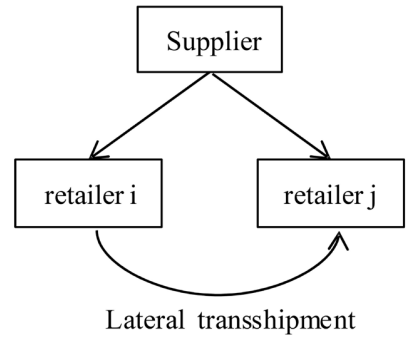

(a) Independent scenario

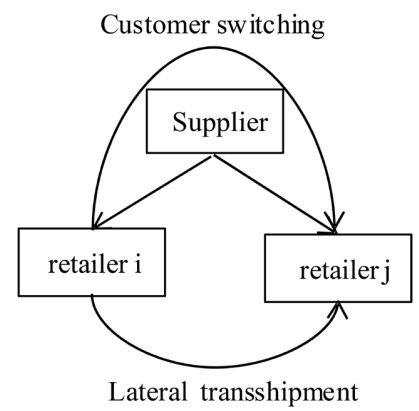

(b) Competitive scenario

Figure 1. Market condition.

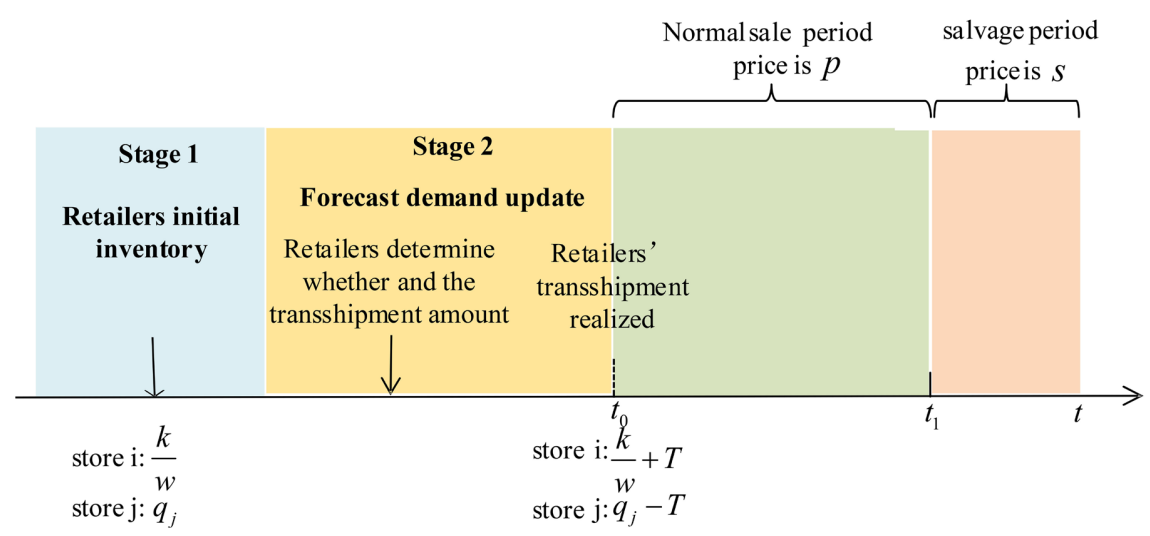

Figure 2. Event sequence.

We first analyze the retailers' preventive transshipment game in stage 2 . Then we will consider how lateral transshipment affects customers purchasing and waiting behavior.

\subsection{Notation and Assumptions}

To decreases the channel conflict between members, we assume that the exogenous retail prices in both retailers are equal: $p_{i}=p_{j}=p$, this strategy has been previously adopted by several researches including Li et al. [25], Cattani et al. [26], Fruchter and Tapiero [27]; and is also consistent with the existing literature [25].

These two retailers face independent demand with known distribution, $D$ is their own individual demand over the selling season. For analysis simply, we assume that the initial inventory of retailer i can't satisfy all of the potential customers of her own market if there is no transshipment, that is, $D_{i}=\frac{k}{w}$; where $k=0$ is the case that retailer i has no ability to stock any inventory at the beginning of the sales season, and has to rely on transshipment to finance her inventory if she wants to continue the operation, otherwise, she must quit the market. In addition, she can only use future revenue to repay such transshipment payment.

In transshipment contract, two retailers agree and commit to transshipment quantity $T$. Transshipment price is exogenous, intuitively, retailer i always want 
to the transshipment price $\lambda$ as lower as wholesale price $w$ to get higher marginal benefit when sell transshipment items to customer. Nevertheless, it is preferable for retailer $\mathrm{j}$ to have higher transshipment price $\lambda$ up to sale price $p$ to receive higher payoff when transship items out, note that, when $\lambda$ equals to $w$, which means retailer $\mathrm{j}$ cannot get extra profit from transshipment.

Some discussions on the model setup are warranted. First, we assume that the retailers' decisions cannot be changed once they are made and committed.

Second, due to retailer $i$ is capital constrained, and we assume that that maximum inventory of retailer $i$ is less than the optimal quantity under traditional newsvendor model, that is, $\frac{k}{w}=q_{i}^{*} \cdot\left(F\left(q_{i}^{*}\right)=\frac{p-w}{p-v}\right)$. Also, she has the right to delay transshipment payment for retailer $j$ until the sales season end, retailer $i$ and retailer $\mathrm{j}$ are information asymmetric, which means they don't know about counter's sales situation.

Third, under competitive market, retailer $\mathrm{j}$ first satisfies unsatisfied customer from retailer $i$, because they cannot get the product when the visit market first time, they eager to get product immediately without hesitation when they turn into another market.

Fourth, transshipment quantity is always less than ordering quantity.

Fifth, both retailers and customers are risk neutral.

Table 1 summarizes the main notations of our model.

Table 1. Notations.

\begin{tabular}{|c|c|}
\hline \multicolumn{2}{|r|}{ parameters } \\
\hline$\lambda$ & Unit transshipment price \\
\hline$w$ & Wholesale price \\
\hline$p$ & Retail price per unit of the product \\
\hline$s$ & Unit salvage value or salvage price \\
\hline V & The product value \\
\hline$k$ & Initial capital of retailer i \\
\hline$\phi$ & The possibility of obtaining product at lower price \\
\hline$N$ & Number of Switcher from retailer i \\
\hline$x$ & Update random demand of retailer i \\
\hline$\theta$ & Low demand risk of retailer $\mathrm{i}$ which retailer $\mathrm{j}$ needs to take \\
\hline$f(x)$ & The probability density function of update random demand $x$ \\
\hline$F(x)$ & The cumulative distribution function of update random demand $x$ \\
\hline$y$ & Update random demand of retailer $j$ \\
\hline$g(y)$ & The probability density function of random demand $y$ \\
\hline$G(y)$ & The cumulative distribution function of random demand $y$ \\
\hline$\Pi$ & The retailer's expected profit \\
\hline$M$ & The expected cash on hand of retailer i before pay transshipment cost at the end of sales season \\
\hline$U$ & Customers utility \\
\hline & Decision variables \\
\hline$T$ & Transshipment amount \\
\hline
\end{tabular}




\section{Transshipment Policy with Different Market}

In this section, we consider the scenario in which the two retailers respectively operate for two markets. To analyze the decisions of transshipment in this scenario, we consider two cases: I. the two retailers do not transship and II. The two retailers transship. The first case involves no transshipment and serves as a benchmark.

\subsection{No Transshipment}

We first analyze the two retailers do not agree on the transshipment contract before they compete in the buyer market, so there is no transshipment even retailer i sells out her own inventory and needs replenishment from retailer $j$, in this situation, when retailer i sells out the product, no matter how her operation is, she has to quit the market, on the other hand, the unsatisfied customers of retailer $i$ have no chance to get the product forever when the market is independent, while some of could switch into retailer j's market to have another chance to get product, therefore, for retailer $i$, no matter how the market is, retailer i' $s$ expect profit is non-differential, that is, expect profit for retailer $i$ is $\Pi_{i}^{N}=p \min \left\{D_{i}, \frac{k}{w}\right\}+s\left(\frac{k}{w}-D_{i}\right)^{+}-k$, for retailer $\mathrm{j}$, if the two markets are independent, he has to liquidate the redundant product with salvage value. Thus, the expect profit of retailer $\mathrm{j}$ under independent market is satisfies

$\Pi_{j}^{I N}=p \min \left\{D_{j}, q_{j}\right\}+s\left(q_{j}-D_{j}\right)^{+}-w q_{j}$, however, he could also sell to unsatisfied customers from retailer, and then liquidate the leftover products with salvage value when the market is competitive, therefore, expect profit for retailer $\mathrm{j}$ under competitive is $\Pi_{j}^{C N}=p \min \left\{D_{j}+S, q_{j}\right\}+s\left(q_{j}-D_{j}-S\right)^{+}-w q_{j}$.

\subsection{Transshipment Policy}

In this section, we consider the transshipment decisions for both retailers. Both retailers have autonomy to determine whether to transship and transshipment quantity. We first analyze retailer i's a transshipment decision and then focus on retailer j's decision.

\section{Retailer i's transshipment decision}

The cash flow of retailer $i$ at the end of sales season and expect profit for two retailers are as follows

$$
M=p \min \left\{D_{i},\left(\frac{k}{w}+T\right)\right\}+s\left(\left(\frac{k}{w}+T\right)-D_{i}\right)^{+}
$$

We summarize the elements in $\pi_{i}^{T}$ below.

$$
\Pi_{j}^{T}=\max \left\{p \min \left\{D_{i},\left(\frac{k}{w}+T\right)\right\}-\lambda T+s\left(\left(\frac{k}{w}+T\right)-D_{i}\right)^{+}, 0\right\}-k
$$

Proposition 1. 1) The optimal proposed transshipment quantity from retailer i's perspective can be expressed as following, which decrease with her initial capital level 


$$
T_{i}^{*}=F^{-1}\left(\frac{p-w}{p-v}\right)-\frac{k}{w}
$$

2) Retailer i's expect profit $\Pi_{i}^{T}$ under transshipment first increases and then decreases with her initial capital level $k$.

All proofs are in the appendix.

Proposition 1 presents the impact of the initial capital level on the equilibrium profit. Surprising, retailers i do not necessarily benefit from an increases in the amount of initial capital, she uses limited ordering and transshipment to satisfy customers, after demand realized, she can earn $(p-w)$ every ordering unit she sold, but lose $(w-s)$ every ordering unit unsold, and earn $(p-\lambda)$ every transshipment unit she sold, but lose $(\lambda-s)$ every transshipment unit unsold. In addition, when $k$ is relatively low, its impact on marginal lose is loom smaller and an increasing $k$ would lead to a higher equilibrium profit. Nevertheless, when $k$ is sufficiently high, due to demand uncertainly and information asymmetric, she may inventory overstock, then increases marginal lose has a more significant effect than on marginal profit of selling. This explains why the overall influence of $k$ on the equilibrium gain is not monotonic and has an interesting inverted U-shape.

Retailer j's transshipment decision

$$
\begin{aligned}
\Pi_{j}^{T}= & p \min \left\{D_{j}+\beta N,\left(q_{j}-T\right)\right\}+s\left(q_{j}-T-D_{j}-\beta N\right)^{+} \\
& +\min \{M, \lambda T\}-w q_{j}, \beta=(0,1)
\end{aligned}
$$

A binary variable $\beta$ is defined to indicate whether there is switching customers from retailer $i$ to retailer $j$.

Lemma 1. Retailer $\mathrm{j}$ does not always prefer to transship, there exist two critical transshipment quantity, default risk point $T_{1}$ and no difference point $T_{2}$, and the maximum transshipment quantity for retailer $\mathrm{j}$ is $T_{2}$. The maximum transshipment quantity for retailer $j$ decreases with the number of switch customers.

1) If $T_{1}<T_{2}$. When transshipment quantity satisfies $T_{j}>T_{2}$, retailer $j$ would be hurt by transshipment cause retailer j's expect profit under transshipment is less than under no transshipment. When $T_{1}<T_{j}<T_{2}$, retailer $\mathrm{j}$ transships out but he has to take some retailer i's default risk, when $0<T_{j}<T_{1}$, retailer $j$ always benefits from transship and need not worry about low demand of retailer' $i$.

2) If $T_{1}>T_{2}$. When transshipment quantity $T_{j}>T_{2}$, retailer $\mathrm{j}$ would be hurt by transshipment cause retailer j' s expect profit under transshipment is less than under no transshipment. When $0<T_{j}<T_{2}$, retailer $\mathrm{j}$ always benefits from transshipment and need not worry about low demand of retailer i.

Where, $M\left(T_{1}\right)=\lambda T_{1}, \Pi_{j}^{T}\left(T_{2}\right)=\Pi_{j}^{N}$.

By lemma 1, retailer $\mathrm{j}$ does not always transship out as much as possible, when proposed transshipment quantity is higher than critical value $T_{2}$, retailer $\mathrm{j}$ will be hurt by transshipment and will not agree to transship, while when transshipment quantity $0<T_{j}<T_{2}$, retailer $\mathrm{j}$ will benefit from transshipment. 
Lemma 1 provides a basis for the intuition, outlined in the introduction, about why over-stocked retailer not always prefers transshipment. Furthermore, from lemma 1 and proposition 1 we have the following proposition.

Proposition 2. There exists $T_{1}$, and $T_{2}$, When $0<T_{j}<T_{1}, \Pi_{j}^{T}$ first increases with $T_{j}$, and then decreases after reaching a maximum level, When $T_{1}<T_{j}<T_{2}$, retailer j's expect profit $\Pi_{j}^{T}$ is decreases with $T_{j}$, but always higher than $\Pi_{j}^{N}$, While when $T_{j}>T_{2}$, retailer j's expect profit equals to $\Pi_{j}^{N}$.

Proposition 2 demonstrates that; transshipment brings lower profit to retailer j when retailer i has default risk. However, when transshipment quantity satisfies $0<T_{j}<T_{2}$, retailer $\mathrm{j}$ transships out always makes higher profit than he does not.

As analysis above, there is a default risk which needs to be taken by retailer $j$ when retailer i cannot afford all transshipment cost, in order to respond to the default risk which affects retailer j's expected profit, we will endeavor to identify it and analyze it.

Proposition 3. We define the retailer i' s default risk is $\theta=\max \left\{\frac{\lambda T-M}{\lambda T}, 0\right\}$, which needs to be taken by retailer $\mathrm{j}$, if $\theta>0$,

1) The default risk $\theta$ increases with transshipment quantity $T$.

2) The default risk $\theta$ decreases with retailer i initial capital $k$.

3) The number of switch customers $N$ has on impact on default risk $\theta$.

By proposition 3, the default risk which retailer $j$ needs to take is the same as long as retailer $j$ agrees to transship no matter how the character of marker is. When retailer $j$ faces retailer i's default risk, he would limit transship out quantity to $T_{1}$ to reduce the level of default risk and make sure himself to earn higher profit by transshipment. This result is the same as the real situation, when downstream requests sufficient large, the firm will not transship out as many as possible to reduce to risk that retailer i cannot pay all the payable in the later transaction.

\section{Transshipment with Different Market}

In this section, we consider the two scenarios in which the retailers sell products for two kinds of market. To analyze the decisions and benefits of transshipment in this scenario, we consider two cases: 1) the retailers transship with independent market and 2) The retailers transship with competitive market.

We consider the scenario in which two retailers are operated independently to maximize their own profit. Each retailer presents a proposed transshipment quantity that they would share or receive with the other retailer. As commonly assumed in a decentralized system [4], the retailer who receives the transshipped items should pay the transshipment price to the retailer that transships out. The transshipment price is fixed and decided based on the negotiation between these two retailers.

\subsection{Transshipment with Independent Market}

We then first analyze the scenario in which retailers transship with independent 
market. Both retailers respectively sell products for two completely independent markets., each of them can't affect the other, especially when retailer i sells out all her inventory, no unsatisfied customers of retailer $i$ could switch into retailer $j$ to get the product immediately, they only stay in retailer i to wait for the transshipment if two retailers agree on a transshipment contract. However, if the transshipment contract did not agree on, that is, there is no transshipment from retailer $j$ to retailer $i$, the unsatisfied customers of retailer $i$ can't get the product anymore. We assume the number of the switch customers is $N$. In dependent market, $\beta=0$, the transshipment profit of retailer $\mathrm{j}$ is,

$$
\Pi_{j}^{I T}=p \min \left\{D_{j},\left(q_{j}-T\right)\right\}+s\left(q_{j}-T-D_{j}\right)^{+}+\min \{M, \lambda T\}-w q_{j}
$$

Proposition 4. when retailer $\mathrm{j}$ determines the optimal transshipment quantity, retailer j's profit first increases and then decreases with $T_{j}$, but eventually keep stable at the profit under no transshipment, and the optimal transshipment quantity of retailer $\mathrm{j}$ is $T_{j}^{I^{*}}=q_{j}-G^{-1}\left(\frac{p-\lambda}{p-s}\right)$, which satisfy $0<T_{j}^{I^{*}}<T_{1}^{I}$, and it increases with transshipment price $\lambda$ but decreases with salvage price $s$.

Proposition 4 shows that the initial capital of retailer i does not impact the transshipment decision of retailer $j$. Moreover, as the transshipment price $\lambda$ increases, transshipment will bring higher profit to retailer $j$, thus retailer $j$ is willing to increase the proposed optimal quantity to earn higher extra profit, but when the salvage price $s$ increases, retailer $\mathrm{j}$ will lower his proposed optimal transshipment quantity due to the loss of unsold product reduces, thus he prefer to stock more to satisfy uncertain demand at price $p$ to make potential higher profit.

\subsection{Transshipment with Competitive Market}

We next look at the situation with competitive market. In the competitive market, if transshipment is rejected, some unsatisfied customers from retailer i may migrate to another market, thus there are two streams of the demand from retailer $\mathbf{j}$, one is his initial uncertain demand $D_{j}$, another is switch customers which are unsatisfied from retailer $\mathrm{i}$, which is assumed $N$. In competitive market, $\beta=1$, the transshipment profit of retailer $\mathrm{j}$ is,

$$
\Pi_{j}^{C T}=p \min \left\{D_{j}+N,\left(q_{j}-T\right)\right\}+s\left(q_{j}-T-D_{j}-N\right)^{+}+\min \{M, \lambda T\}-w q_{j}
$$

We then investigate whether there exists an optimal transshipment quantity with and the relationship of the transshipment quantity and the number of switch number.

Proposition 5. The optimal transshipment quantity $T_{j}^{C^{*}}$ from retailer j's perspective with competitive market,

$T_{j}^{C^{*}}(M>\lambda T)=q_{j}-N-G^{-1}\left(\frac{p-\lambda}{p-s+N(p-1)}\right)$, which decreases with the number of switch customer $N$. 
Proposition 5 indicates that proposed optimal transshipment quantity at retailer $j$ is determined based on the cost parameters and the number of switch customers. Given the optimal transshipment strategy, the proposed optimal transshipment quantity decreases with the number of switch customers. That is, when there exist switch customers, retailer $j$ would reduce his transshipment quantity to satisfy more switch customers.

From the optimal transshipment decision policies proposed above, we get the follow proposition.

Proposition 6. Given the optimal transshipment strategy with different market,

1) The optimal transshipment quantity with independent market is higher than it with competitive market.

2) retailer j's expect profit with competitive market is always higher than its with independent market, and its first increases and then decreases with retailer i' s capital level $T$, and the expect profit under both independent and competitive market scenarios finally converge to those under no transshipment.

From proposition 6. I, retailer j's optimal transshipment quantity is higher with independent market, cause when the market is competitive, unsatisfied customers of retailer $i$ will switch to retailer $j$, the marginal profit sold one product to unsatisfied customers is high than transship out for retailer $j$, therefore, retailer $j$ would reduce transshipment quantity to make sure more inventory to satisfy potential switch customers from retailer i with competitive market.

Proposition 6. II shows that retailer j's profitability increases as the number of switchers increases, and its higher on competitive market. This is not surprising, because an increased number of switch customers leads to a larger amount of market demand. This understanding allows the retailer $j$ to potentially reject transshipment request to sell to switch customers to earn higher revenues at retail price $p$. The increasing profitability is, thus, explained. Nevertheless, when transshipment quantity is higher than a threshold, retailer $j$ will reject transship due to the default risk is too high, therefore, the expect profit finally converge to those under no transshipment as the proposed transshipment quantity increase.

Transshipment is not always beneficial for retailers, retailer i earns a higher profit when she is severely capital constrained and transshipment quantity is in the middle, however, when ordering does not limit by capital so much, the increases of transshipment will decrease retailer i's profit. On the other hand, transshipment beneficial for retailer $j$ when transshipment quantity is not very high, and makes a higher profit with competitive market.

\subsection{Sensitivity Analyses}

In this section, sensitivity analyses on the cardinal parameters of the model will be carried out and their impact on the decision variables and on the transshipment quantity and profitability of the retailers will be discussed.

The data-sets in this work are set according to Rudi et al. [1]. In addition, val- 
ues of parameters satisfy all assumptions and requirement of our model. It should be mentioned that since some parameters are new to the literature of lateral transshipment and switch customers, such as $N$, and also due to the contributions made to existing literature, we need to alter the data-sets used by precious studies to become consistent with our work, In our numerical experiment, the related parameters have values as follow: $p=4, \lambda=3, w=3, s=1$, the demand is identically and independently distributed for these two retailers, a uniformly distributed demand is assumed for each of these two retailers, that is $D \sim U[0,1]$, given that competitive market exists switch customers, we assume the number of switch customers is $N \sim U[0,1]$, but is less than the total realized demand of retailer $\mathrm{i}$.

We first analyze the impact of parameters on retailer j's transshipment decision. From lemma 1 and proposition 2, we get Figure 3. Figure 3(a) demonstrates the relationship between the maximum transshipment $T_{2}$ quantity and the initial capital level of $k$, Figure $3(\mathrm{~b})$ depicts the relationship between the maximum transshipment quantity $T_{2}$ and the number of switchers $N$. We can obtain Figure 4 by Proposition 4 and Proposition 5, with all above parameters, Figure 4(a) demonstrates the relationship between the proposed optimal transshipment quantity $T_{j}^{*}$ and the initial capital level of $k$, Figure $4(\mathrm{~b})$ depicts the relationship between the proposed optimal transshipment $T_{j}^{*}$ quantity and the number of switcher $N$.

From Figure 3, the proposed maximum transshipment quantity of retailer $j$ is always higher with independent market, and it decreases with the retailer i's initial capital $k$ and the number of switch customers. Furthermore, Figure 3(a) indicates that when retailer i' $s$ initial capital is sufficient high, target inventory can be satisfied by her initial capital, there is no needs to transship in, thus the maximum transshipment quantity of retailer $j$ reduces a little. From Figure $3(b)$, as the increases of the number of switch customer, more unsatisfied customers switch to retailer $j$ to get product immediately, therefore, retailer $j$ will limit the transshipment quantity to make sure that there is enough inventory to serve unsatisfied customers at retail price $p$, which brings him higher profit than transshipping out at transshipment price $\lambda$.

Figure 4 shows the proposed optimal transshipment quantity of retailer i decreases with initial capital level $k$, while the proposed optimal transshipment quantity of retailer $j$ is not affected by the initial capital level of retailer $i$, and it is always highest with independent scenario. one counter-intuitive result is that proposed optimal transshipment quantity of retailer $i$ is lower than retailer $j$ ' $s$ with competitive market when her capital level $k$ is beyond the threshold from Figure 4(a), and the proposed optimal transshipment quantity of retailer $j$ with competitive market is lower than retailer i's when the number of switch customers is beyond the threshold from Figure 4(b), which identify with the result we proposed above, marker competition will induce over-stock retailer transship our less or even zero as the increase of switch customers. 


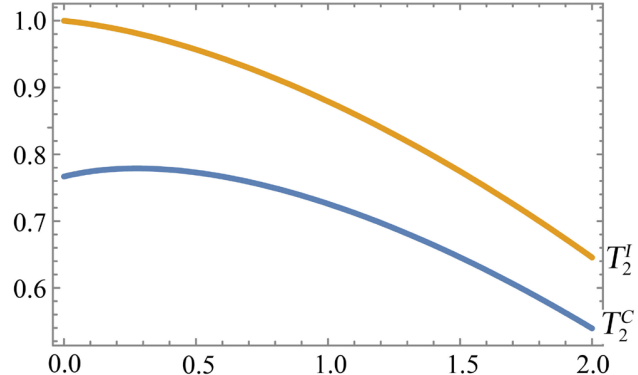

(a) Impact of $k$

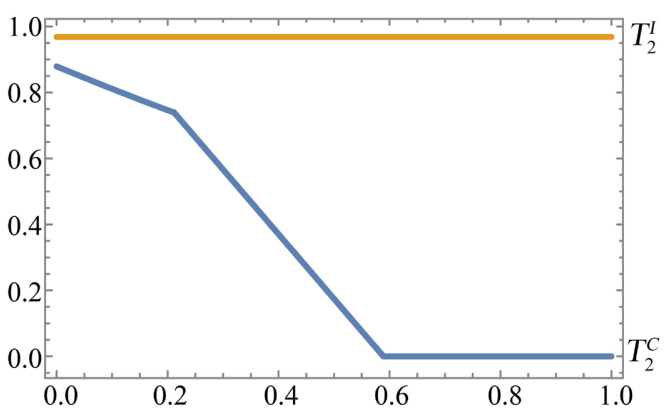

(b) Impact of $N$

Figure 3. Impact of parameters on retailer j's proposed maximum transshipment quantity.

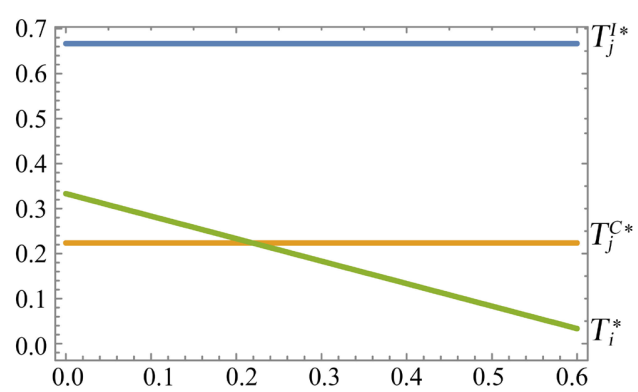

(a) Impact of $k$

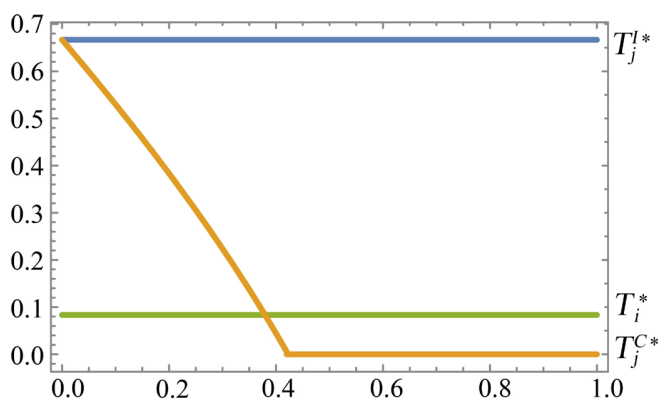

(b) Impact of $N$

Figure 4. Impact of parameters on retailers' optimal proposed transshipment quantity.

Proposition 4 and Figure 4 indicate that given the optimal transshipment strategy with different market, retailer $j$ prefer to transship less with competitive market, which is intuitive that market competition induce retailer $j$ inventory more and lower the transshipment quantity to satisfy more switcher to make an extra profit at sale price $p$, which is higher than transshipping out at transshipment price $\lambda$.

Figure 5 indicates that retailer $j$ ' s optimal transshipment quantity is higher with independent market than with competitive market, this is intuitive that market competition will lower the transshipment quantity. From Figure 5(a), retailer $j$ ' s profit with competitive market is higher than independent market when $T<T_{1}$, but the difference of retailer $j$ ' $s$ expect profit between competitive and independent market reduce with the increases of proposed transshipment quantity, even independent market will lead a higher profit when $T_{1}<T<T_{2}^{C}$, however, the difference sudden increases and competitive market brings a higher profit to retailer $\mathrm{j}$ when $T>T_{2}^{C}$, where there is no transshipment between retailers. On the other hand, it is clear from Figure 5(b) that when market competition is fierce (in this case, $N=0.3$ ), retailer $\mathrm{j}$ will not transship out when proposed transshipment quantity is beyond default risk point, thus there exists two kinds of strategy for retailer j, i.e., transshipping out without retailer i' s default risk or no transshipment, and retailer $j$ ' s profit with competition market is always higher than with independent market. 


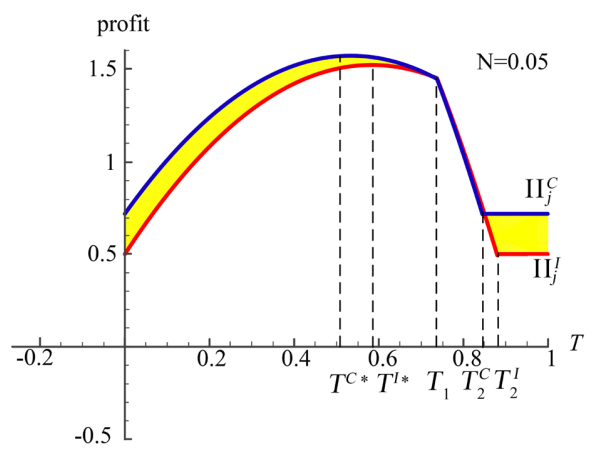

(a) $N=0.05$

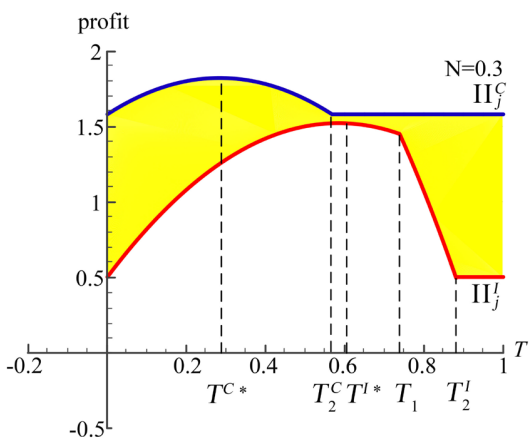

(b) $N=0.3$

Figure 5. Impact of the transshipment quantity on retailer $j$ ' s profit.

Market competition may increases the profit of retailer $j$ when retailer $j$ transship out without retailer i's default risk or do not transship out, due to unsatisfied customers switch to retailer $j$ from retailer $i$, which increases the potential total demand of retailer $j$, in this case, if retailer $j$ still transships out with retailer i' s default risk, competitive market brings lower profit than independent market, due to he may lose some profit which selling product to switch customers instead of transshipment.

\section{Numerical Analyses}

In this section, a computational experiment to supplement the analytical results from the previous section as well as to provide additional managerial insights is further provided. The experiment will indicate the impact of capital level and the number of switch customer on profit, and the usefulness and efficacy of the transshipment contract proposed to make better performance. The proposed model with independent market and competitive market will be evaluated.

\subsection{Impact of the Capital Constraint on Profit}

Combining with the above parameters, we can obtain Figure 6 and Figure 7, indicate the impact of initial capital $k$ and transshipment quantity $T$ on retailer's expected profit. We assume the initial capital satisfy $k \in(0,2)$. Specifically, $k=2$ denotes complete capital sufficient, whereas $k=0$ denotes complete capital constrained.

Figure 6 presents retailer i's profit under different transshipment quantity and different initial capital level. For a specific proposed transshipment quantity, the retailer i's profit first increases with initial capital level, and then decreases after reaching a maximum level, we can observe that the profit decreases to a negative value at different rate for different transshipment value. For a specific capital level ( $k<0.8$ before transshipment may benefit for retailer i), the profit first increases and then decreases as $T$ increases. This counter-intuitive result is caused by the uncertain demand distribution. Since the profit varies among different realized demand, the higher realized demand led to higher profit by lower the overstock inventory at the end of sales season. 


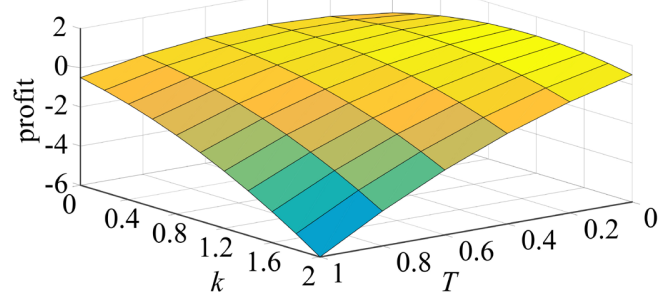

Figure 6. Impact of transshipment quantity and capital constrains on retailer i's profit.

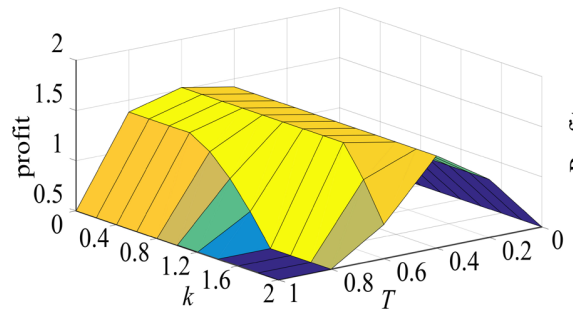

(a) $N=0$

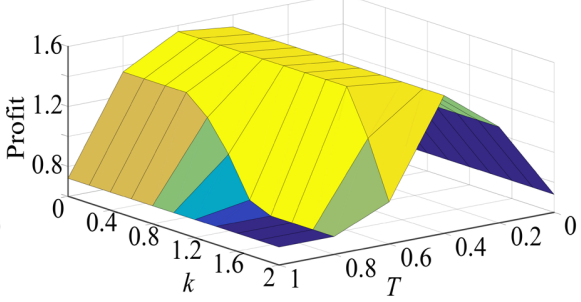

(b) $N=0.05$

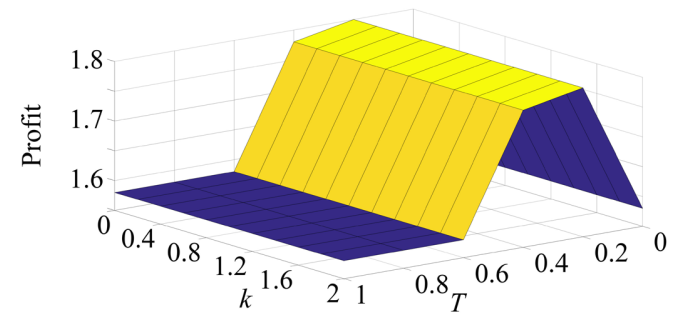

(c) $N=0.3$

Figure 7. Impact of transshipment quantity and capital constrains on retailer j's profit.

Figures 7(a)-(c) indicate the impact of initial capital $k$ and transshipment quantity $T$ on profit under different condition of switch customers

Figure 7(a) and Figure 7(b) show the retailer j' s profit under different transshipment quantity and initial capital level when there are no switch customers that is, $N=0$, or the number of switch customer is small, in this case,

$N=0.05$ for a specific proposed transshipment quantity. When $T<0.6$, the retailer j's profit keeps unchanged as the increases with $k$. When $T=0.6$, the retailer j's profit keeps unchanged until $k=1.8$ and then takes a dip. When $0.6<T<0.8$, the retailer j's profit keeps unchanged until $k=0.8$ and then decreases to coverage to the profit under no transshipment, and the rate to coverage to the profit under no transshipment increase as $T$ increase. For a specific transshipment quantity $k$, the profit first increases with $T$, and then decreases converge into the result under no transshipment. As we can observe in this figure, the profit converges to its maximum at different rate for different proposed transshipment quantity.

Figure 7 (c) shows that the retailer j' s profit is increases as long as the transshipment quantity is low, and it does not change as the increases with initial 
capital level

\subsection{Impact of the Switch Customers on Expect Profit}

Combining with the above parameters, we can get Figure 8 by proposition 6 . Figure 8 illustrates the impact of the number of switch customers $N$ and transshipment quantity $T$ on retailer $j$ ' s expect profit.

Figure 8 shows the retailer $j$ ' s profit under different transshipment quantity with switch customers who cannot be satisfied from retailer i market. For a specific proposed transshipment quantity, the retailer j's expect profit first increases with $N$, and then decreases after reaching a maximum level. For a specific switch customer amount, when the number of switch customers is lower than mean, $N<0.5$, the retailer j' s profit first increases with $N$, and then decreases after reaching its maximum. While when the number of switch customers is lower than mean, $N>0.5$, the retailer j' s profit keeps constant with $N$.

The switch number is affected retailer j's profitability through the transshipment policy. When the number of switch customers changes, the optimal transshipment policy responds by adjusting the transshipment quantity. Recall that retailer $\mathrm{j}$ can earn more profit from satisfying a unit of switched demand than a unit of the transshipment demand due to retail price $p$ is higher than transshipment price $\lambda$, which causes marginal profit increases, thus it is possible for retailer $\mathrm{j}$ to improve his profitability while fulfilling a slightly smaller amount of total demand at retail price $p$ as long as there exists switch customers. This explains the observed increases of retailer j's profit.

\subsection{Managerial Insight}

This subsection provides significant managerial insights for retailers in decentralized inventory system considering lateral transshipment.

Insight 1. For the transshipment contract with capital constrained, the expect profit of the two retailers increases with transshipment quantity until it achieves the maximum, and then decreases and converge to the result under no transshipment, which means rational transshipment are benefit two retailers, while both of them are not always prefer to transshipment.

Insight 2. For the transshipment contract with switch customers, retailer $j$ will lower the transshipment quantity when there exist switch customers, which means market competition will reduce transshipment quantity.

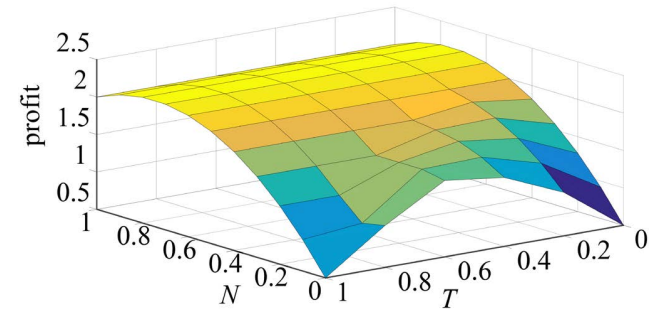

Figure 8. Impact of transshipment quantity and switch number on retailer j's expect profit. 


\section{Conclusions}

This research primarily focuses on lateral transshipment policies in two independent retailers, one is capital constrained but another is not, we then investigate the optimal dynamic transshipment decisions for two retailers under both independent and competitive market scenarios. We show that if the two retailers' market is independent, the overstock retailer always benefits from transshipment while the under-stock shore may be hurt by transshipment. Whether the under-stock retailer benefits from or hurt by transshipment depends on the initial capital level and transshipment quantity. If the markets are competitive, the movement of switch customers impacts on over stock retailer's transshipment decision. When the number of switch customer is larger than a certain threshold, the over-stock retailer can always reject transshipment. When the number of switch customers is constrained, the level of transshipment quantity plays an important role in over stock retailer's transshipment decision. Both retailers prefer transshipment if the transshipment quantity is smaller than a threshold value.

This research provides insights for managers to wisely choose an optimal transshipment policy in different market conditions. The maximum transshipment quantity and optimal transshipment quantity under competitive scenario are less than those under independent scenario, and competitive scenario is more restrict effective for transshipment decisions when the initial capital of under-stock retailer is sufficient low. It shows that the transshipment conditions under the competitive scenario are stricter than those under in the independent scenario. It implies that the market competition is a possible incentive for over stock retailer to reduce transshipment quantity. Given the demand distribution, transshipment price, initial ordering and the number of switch customers, the result for comparisons can be determined with the proposed method.

This article assumes that the scale of consumer switching is a fixed constant, but in practice the number of consumer switching may be random, and in practice, there may be more than two retailers in a competitive market. It can be extended in a number of possible ways. First, in our study, we assumed that the ordering quantity is not a decision variable. When this assumption is relaxed, and the over stock retailer can determine the ordering quantity, the resulting transshipment condition can be more sophisticated. Furthermore, we have assumed that the retail price and transshipment price are predetermined, it would be worthwhile to investigate how the price influences the transshipment decision policy.

\section{Acknowledgements}

This work has supported by the Nation Natural Science Foundation of China (71572154), and Service Science and Innovation Key Laboratory of Sichuan Province (KL2104). 


\section{Conflicts of Interest}

The authors declare no conflicts of interest regarding the publication of this paper.

\section{References}

[1] Rudi, N., Kapur, S. and Pyke, D.F. (2001) A Two-Location Inventory Model with Transshipment and Local Decision Making. Management Science, 47, 1668-1680. https://doi.org/10.1287/mnsc.47.12.1668.10235

[2] Feng, P., Wu, F., Richard, Y.K.F., Jia, T. and Zong, W. (2019) The Order and Transshipment Decisions in a Two-Location Inventory System with Demand Forecast Updates. Computers \& Industrial Engineering, 135, 53-66. https://doi.org/10.1016/j.cie.2019.04.043

[3] Feng, P.P., Wu, F., Richard, Y.K.F. and Jia, T. (2018) Evaluation of Two Transshipment Policies in a Two-Location Decentralized Inventory System under Partial Backordering. Transportation Research Part E: Logistics and Transportation Review, 118, 207-224. https://doi.org/10.1016/j.tre.2018.07.010

[4] Hu, X.X., Duenyas, I. and Kapuscinski, R. (2007) Existence of Coordinating Transshipment Prices in a Two-Location Inventory Model. Management Science, 53, 1289 1302. https://doi.org/10.1287/mnsc.1060.0694

[5] Shao, X.F. (2018) Production Disruption, Compensation, and Transshipment Policies. Omega, 74, 37-49. https://doi.org/10.1016/j.omega.2017.01.004

[6] Petruzzi, N.C. and Dada, M. (1999) Pricing and the Newsvendor Problem: A Review with Extensions. Operations Research, 47, 183-194.

https://doi.org/10.1287/opre.47.2.183

[7] Lariviere, M.A. and Porteus, E.L. (2001) Selling to the Newsvendor: An Analysis of Price-Only Contracts. Manufacturing \& Service Operations Management, 3, 293-305. https://doi.org/10.1287/msom.3.4.293.9971

[8] Cachon, G.P. (2003) Supply Chain Coordination with Contracts. In: Handbooks in Operations Research and Management Science, Vol. 11, Elsevier, Amsterdam, 227339. https://doi.org/10.1016/S0927-0507(03)11006-7

[9] Kouvelis, P. and Zhao, W. (2016) Supply Chain Contract Design under Financial Constraints and Bankruptcy Costs. Management Science, 62, 2341-2357.

https://doi.org/10.1287/mnsc.2015.2248

[10] Yang, S.A. and Birge, J.R. (2017) Trade Credit, Risk Sharing, and Inventory Financing Portfolios. Management Science, 64, 3667-3689. https://doi.org/10.1287/mnsc.2017.2799

[11] Xu, X. and Birge, J.R. (2004) Joint Production and Financing Decisions: Modeling and Analysis. Working Paper. https://ssrn.com/abstract=652562 https://doi.org/10.2139/ssrn.652562

[12] Lai, G., Debo, L.G. and Sycara, K. (2009) Sharing Inventory Risk in Supply Chain: The Implication of Financial Constraint. Omega, 37, 811-825. https://doi.org/10.1016/j.omega.2008.06.003

[13] Caldentey, R. and Hen, X. (2011) The Role of Financial Services in Procurement Contracts. In: Boyabatli, O., Dong, L.X. and Kouvelis, P., Eds., Handbook of Integrated Risk Management in Global Supply Chains, Wiley, Hoboken, 289-326. https://doi.org/10.1002/9781118115800.ch11

[14] Kouvelis, P. and Zhao, W. (2011) The Newsvendor Problem and Price-Only Con- 
tract When Bankruptcy Costs Exist. Production and Operations Management, 20, 921-936. https://doi.org/10.1111/j.1937-5956.2010.01211.x

[15] Yang, S.A., Birge, J.R. and Parker, R.P. (2015) The Supply Chain Effects of Bankruptcy. Management Science, 61, 2320-2338.

https://doi.org/10.1287/mnsc.2014.2079

[16] Tunca, T.I. and Zhu, W. (2017) Buyer Intermediation in Supplier Finance. Management Science, 64, 5631-5650. https://doi.org/10.1287/mnsc.2017.2863

[17] Tang, C.S., Yang, S.A. and Wu, J. (2018) Sourcing from Suppliers with Financial Constraints and Performance Risk. Manufacturing \& Service Operations Management, 20, 70-84. https://doi.org/10.1287/msom.2017.0638

[18] Shao, J., Krishnan, H. and McCormick, S.T. (2011) Incentives for Transshipment in a Supply Chain with Decentralized Retailers. Manufacturing \& Service Operations Management, 13, 361-372. https://doi.org/10.1287/msom.1110.0326

[19] Das, C. (1975) Supply and Redistribution Rules for Two-Location Inventory Systems: Oneperiod Analysis. Management Science, 21, 765-776.

https://doi.org/10.1287/mnsc.21.7.765

[20] Zou, L., Dresner, M. and Windle, R.A. (2010) A Two-Location Inventory Model with Transshipments in a Competitive Environment. International Journal of Production Economics, 125, 235-250. https://doi.org/10.1016/j.ijpe.2010.03.001

[21] Paterson, C., Kiesmüller, G., Teunter, R. and Glazebrook, K. (2011) Inventory Models with Lateral Transshipments: A Review. European Journal of Operational Research, 210, 125-136. https://doi.org/10.1016/j.ejor.2010.05.048

[22] Çömez, N., Stecke, K.E. and Metin, Ç.M. (2012) Multiple In-Cycle Transshipments with Positive Delivery Times. Production and Operations Management, 21, 378-395. https://doi.org/10.1111/j.1937-5956.2011.01244.x

[23] Liang, C., Sethi, S.P., Shi, R. and Zhang, J. (2014) Inventory Sharing with Transshipment: Impacts of Demand Distribution Shapes and Setup Costs. Production and Operations Management, 23, 1779-1794. https://doi.org/10.1111/poms.12197

[24] Shi, M. (2019) Research on Order-Inventory Transshipment Mechanism in DualChannel Distribution Supply Chain. Open Journal of Business and Management, 7, 1120-1130. https://doi.org/10.4236/ojbm.2019.73077

[25] Li, B., Zhu, M., Jiang, Y. and Li, Z. (2016) Pricing Policies of a Competitive DualChannel Green Supply Chain. Journal of Cleaner Production, 112, 2029-2042. https://doi.org/10.1016/j.jclepro.2015.05.017

[26] Cattani, K., et al. (2006) Boiling Frogs: Pricing Strategies for a Manufacturer Adding an Internet Channel. Production and Operations Management, 15, 40-56. https://doi.org/10.1111/j.1937-5956.2006.tb00002.x

[27] Fruchter, G.E. and Tapiero, C.S. (2005) Dynamic Online and Offline Channel Pricing for Heterogeneous Customers in Virtual Acceptance. International Game Theory Review, 7, 137-150. https://doi.org/10.1142/S0219198905000454 


\section{Appendix}

Proof of proposition 1

Proof of the monotonicity of $T_{i}^{*}$ in $k$

Taking the first-order derivative of $\Pi_{i}^{T}$ with respect to $T$, we get

$$
\frac{\mathrm{d} \Pi_{i}^{T}}{\mathrm{~d} T}=-\int_{0}^{\frac{k}{w}+T} f(x)(p-\lambda) \mathrm{d} x+\int_{0}^{\frac{k}{w}+T} f(x)(s-\lambda) \mathrm{d} x-\lambda+p
$$

Taking the first-order derivative of $\Pi_{i}^{T}$ with respect to $k$ yields,

$$
\frac{\mathrm{d}^{2} \Pi_{i}^{T}}{\mathrm{~d}^{2} T}=(s-p) F\left(\frac{k}{w}+T\right)<0
$$

Solving Equation (A.1) equals zero, we get:

$$
T_{i}^{*}=F^{-1}\left(\frac{p-w}{p-v}\right)-\frac{k}{w},
$$

It is clear that the optimal transshipment quantity $T_{i}^{*}$ decreases with $k$ due to $\frac{\mathrm{d} \Pi_{i}^{T}}{\mathrm{~d} k}=-\frac{1}{w}<0$.

Proof of the concavity of $\Pi_{i}^{T}$ in $k$

Taking the first-order derivative of $\Pi_{i}^{T}$ with respect to $k$ yields,

$$
\frac{\mathrm{d}^{2} \Pi_{i}^{T}}{\mathrm{~d}^{2} k}=-\frac{(p-s) F\left(\frac{k}{w}+T\right)}{w^{2}}<0 .
$$

\section{Proof of lemma 1}

Whether retailer $\mathrm{j}$ transship nor not? The no difference point yields

$$
\begin{aligned}
& p \min \left\{D_{j}+\beta N,\left(q_{j}-T\right)\right\}+s\left(q_{j}-T-D_{j}-\beta N\right)^{+}+\min \{M, \lambda T\}-w q_{j} \\
& =p \min \left\{D_{j}+\beta N, q_{j}\right\}+s\left(q_{j}-D_{j}-\beta N\right)^{+}-w q_{j}
\end{aligned}
$$

The left-hand-side first increasing and then decreasing with $T_{j}$, and the right-hand-side remaining unchanged as $T_{1}$ increase, so the Equation (A.3) has a unique solution, thus there exists a no difference point $T_{1}$, where $\Pi_{j}^{T}\left(T_{2}\right)=\Pi_{j}^{N}$, when $0<T_{j}<T_{2}$, retailer $\mathrm{j}$ will benefit from transshipment, while when $T_{j}>T_{2}$, retailer $j$ will be hurt by transshipment and will not agree to transship.

Under transshipment, retailer i should to pay to retailer $\mathrm{j} \lambda T$, which is also retailer j's ideal receivable (full receivable), however, due to the effect of uncertain demand, retailer i's cash flow at the end of sales period is $M$, so the payoff of retailer $\mathrm{i}$ is $\min \{M, \lambda T\}$, there is a default risk point $T_{1}$. Firstly, if $T_{1}<T_{2}$, when $0<T_{j}<T_{1}$, retailer $\mathrm{j}$ benefits transshipping out without retailer i's default risk, however, When $T_{1}<T_{j}<T_{2}$, retailer $j$ transship out but he has to take some retailer i's default risk, that is $M<\lambda T$, then retailer $\mathrm{j}$ will not get the full receivable due to retailer $i$ is limited liability, furthermore, as the transshipment quantity increases, retailer j's expect profit reduce but transshipment still benefit him until his expect profit decreases to profit under no transshipment. Never- 
theless, if $T_{1}>T_{2}$, which means transshipment with retailer i's default risk always hurt retailer $j$, that is ,there are only two kinds of situation, transshipment without retailer i's default risk and no transshipment, When $0<T_{j}<T_{2}$, retailer $\mathrm{j}$ always benefit from transshipment and need not worry about low demand of retailer $\mathrm{i}$, When $T_{j}>T_{2}$, retailer $\mathrm{j}$ will hurt by transshipment and will not agree to transshipment.

Proof of proposition 2

When $0<T_{j}<T_{1}$, retailer j's expect profit function is,

$$
\Pi_{j}^{I T}(T(M>\lambda T))=p \min \left\{D_{j},\left(q_{j}-T\right)\right\}+s\left(q_{j}-T-D_{j}\right)^{+}+\lambda T-w q_{j},
$$

taking the first-order and second-order derivative of $\Pi_{j}^{I T}$ with respect to $T_{j}$ yields,

$$
\begin{gathered}
\Pi_{j}^{I T \prime}(T(M>\lambda T))=(\lambda-p)+(p-s) G\left(q_{j}-T\right), \\
\Pi_{j}^{I T / \prime}(T(M>\lambda T))=-(p-s) G\left(q_{j}-T\right)<0,
\end{gathered}
$$

The expect profit $\Pi_{j}^{I T}(T(M>\lambda T))$ is concave in $T_{j}$, thus there exist the optimal transshipment quantity,

$$
T_{j}^{I^{*}}(M>\lambda T)=q_{j}-G^{-1}\left(\frac{p-\lambda}{p-s}\right) .
$$

When $T_{1}<T_{j}<T_{2}$, retailer j's expect profit function is,

$$
\Pi_{j}^{I T}(T(M<\lambda T))=p \min \left\{D_{j},\left(q_{j}-T\right)\right\}+s\left(q_{j}-T-D_{j}\right)^{+}+M-w q_{j},
$$

The expected profit $\Pi_{j}^{I T}(T(M<\lambda T))$ decreases with transshipment $T_{j}$ when $T_{1}<T_{j}<T_{2}$, so the optimal transshipment quantity is the intersection of $\Pi_{j}^{I T}(T(M>\lambda T))$ and $\Pi_{j}^{I T}(T(M<\lambda T))$, also is the intersection of $M$ and $\lambda T$, that is, the optimal transshipment quantity when retailer $i$ has default risk is $T_{j}^{I^{*}}(M<\lambda T)=\frac{M}{\lambda}$, it is easy to verify that $\Pi_{j}^{I T}(T(M>\lambda T))>\Pi_{j}^{I T}(T(M<\lambda T))$, thus the optimal transshipment quantity of retailer $\mathrm{j}$ is $q_{j}-G^{-1}\left(\frac{p-\lambda}{p-s}\right)$.

Proof of proposition 3

1) The first order derivative of $\theta$ with respect to $T$ is

$\frac{\mathrm{d} \theta}{\mathrm{d} T}=\frac{T w(p-s) F\left(\frac{k}{w}+T\right)+k p}{\lambda T^{2} w}>0$.

2) The first order derivative of $\theta$ with respect to $k$ is $\frac{\mathrm{d} \theta}{\mathrm{d} k}=\frac{-p \int_{0}^{\frac{k}{w}+T} f(x) \mathrm{d} x+s \int_{0}^{\frac{k}{w}+T} f(x) \mathrm{d} x+p}{\lambda T w}<0$.

3) The second order derivative of $\theta$ with respect to $N$ is $\frac{\mathrm{d} \theta}{\mathrm{d} N}=0$. Note that, in competitive market, although there is some unsatisfied customer switch into retailer $j$ when retailer $i$ has sold out all her inventory and had no ability to rep- 
lenish inventory, which increases retailer j's market demand, there is no effect on retailer i's market due to those character customer only emerge after retailer i ends her sales season. So the handing cash of retailer $i$ at the end of sales season is, $M=p \min \left\{D_{i},\left(\frac{k}{w}+T\right)\right\}+s\left(\left(\frac{k}{w}+T\right)-D_{i}\right)^{+}$, for retailer $\mathrm{j}$, the receivable is $\lambda T$, the transshipment cost is $w T$, so the critical value about can obtain by $M(\underline{T})=\lambda \underline{T}$, therefore, the low demand risk retailer j needs to take $\theta=\frac{\lambda T-M}{\lambda T}$ is non-differential.

Proof of proposition 4 and proposition 5

Taking the first-order derivative of $\Pi_{j}^{C T}$ with respect to $T$, we obtain

$$
\Pi_{j}^{C T /}(T)=p-s+N(p-1) G\left(q_{j}-N-T_{j}^{C^{*}}(M>\lambda T)\right)-p-\lambda
$$

The optimal transshipment quantity when retailer $j$ has no default risk with competitive market can be found by setting Equation (A.8) to zero.

$$
T_{j}^{C^{*}}=q_{j}-N-G^{-1}\left(\frac{p-\lambda}{p-s+N(p-1)}\right),
$$

if $N=0$, the situation reduces to the independent market, that is,

$$
T_{j}^{I^{*}}=q_{j}-G^{-1}\left(\frac{p-\lambda}{p-s}\right),
$$

Taking the first-order derivative of optimal transshipment quantity $T_{j}^{I^{*}}$ with respect to $\lambda$ and $s$ yields,

$$
\begin{gathered}
T_{j}^{I^{* \prime}}(\lambda)=\frac{1}{(p-s) g\left(G^{-1}\left(\frac{p-\lambda}{p-s}\right)\right)}>0, \\
T_{j}^{I^{*}}(s)=\frac{\lambda-p}{(p-s)^{2} f^{\prime}\left(f^{-1}\left(\frac{p-\lambda}{p-s}\right)\right)}<0,
\end{gathered}
$$

Taking the first-order derivative of optimal transshipment quantity $T_{j}^{C^{*}}$ with respect to $N$ yields

$$
T_{j}^{C^{* /}}(N)=-1+\frac{(p-1)(p-\lambda)}{(s+N-p(1+N))^{2} g\left(G^{-1}\left(\frac{p-\lambda}{p-s+(p-1) N}\right)\right)}<0
$$

\section{Proof of proposition 6}

From proposition 5, It is easy to find $T_{j}^{C *}$ decreases with $N$, thus the optimal transshipment quantity satisfied $T_{j}^{C^{*}}<T_{j}^{I^{*}}$. When retailer $j$ transships out without default risk, the expected profit of retailer $j$ is

$$
\Pi_{j}^{T}=p \min \left\{D_{j}+N,\left(q_{j}-T\right)\right\}+s\left(q_{j}-T-D_{j}-N\right)^{+}+\lambda T-w q_{j}
$$

The profit difference between competitive market and independent market is 


$$
\Delta \Pi_{j}^{T}=\Pi_{j}^{C T}-\Pi_{j}^{I T}
$$

When $T=0, \Delta \Pi_{j}^{T}(T=0)=(p-s) G\left(q_{j}-N\right)>0$ because retailer $\mathrm{j}$ has sufficient inventory, thus the expected profit with competitive market is higher than with independent market.

Taking the first-order derivative of optimal transshipment quantity $\Delta \Pi_{j}^{T}$ with respect to $T$ yields

$$
\frac{\mathrm{d} \Delta \Pi_{j}^{T}}{\mathrm{~d} T}=(p-s)\left[G\left(q_{j}-T_{j}-N\right)-G\left(q_{j}-T_{j}\right)\right],
$$

Observe that $G\left(q_{j}-T_{j}-N\right)<G\left(q_{j}-T_{j}\right)$ because $q_{j}-T_{j}-N<q_{j}-T_{j}$, thus $\frac{\mathrm{d} \Delta \Pi_{j}^{T}}{\mathrm{~d} T}<0$, the profit difference between competitive market and independent market decreases with $T$. therefore, the expected profit with competitive market is always higher than with independent market, but the profit difference between two markets decreases as transshipment quantity increase. 